\title{
The use of satellite data for monitoring rivers in the Amu Darya basin
}

\author{
Ildar Mukhamedjanov*, Anna Konstantinova and Evgeniy Loupian \\ Space Research Institute of the RAS (IKI), 84/32 Profsoyuznaya, Moscow, Russia, 117997
}

\begin{abstract}
The paper explores the organization of satellite monitoring of water bodies in Central Asia on the example of the Amu Darya river in a specialized satellite monitoring system EcoSatMS (http://suvo.geosmis.ru). The potential and prospects of using the new technology of virtual gauging stations to control the state of water bodies, as well as restoring the values of daily runoff at a point remote from the ground station for some distance are highlighted. Evaluation of the effectiveness of the implementation of the virtual gauging stations technique in flow of automated calculations allows to take the research as a basis for further development of individual tools for analyzing satellite observation time series and the EcoSatMS in general.
\end{abstract}

\section{Introduction}

The typical feature of the water resources of the Central Asian region are transboundary rivers. The Amu Darya is the most affluent river in Central Asia, which is at the same time the basis of the water potential for the southern part of the region. The transboundary waters of the Amu Darya play an important role in irrigation and agriculture, in particular for Uzbekistan. Under such conditions, satellite data help to objectively and timely assess the state of the certain parts of the river bed and water bodies of other origin (lakes and water reservoirs). Modern remote sensing systems make it possible to organize the acquisition of observation series of natural and anthropogenic objects with a time frequency of several days. To solve the problems of complex satellite monitoring of water bodies in Uzbekistan and Central Asia in general, a special satellite monitoring system EcoSatMS (Ecosystem Satellite Monitoring service, http://suvo.geosmis.ru) has been developed at the Space Research Institute of the Russian Academy of Sciences [2].

The system is based on the "IKI-Monitoring" center for collective use infrastructure [1]. is the part of the Sozvezdie-Vega services family (http://sozvezdie-vega.ru), it is developed and maintained at the Space Research Institute of the Russian Academy of Sciences (IKI). The map interface of the service is adapted for the territory of Uzbekistan and neighboring countries, the basic cartographic layers of the region boundaries, road networks, water bodies, settlements, the boundaries of the catchments of rivers in Central Asia are integrated [3]. The long-term data archives with a depth of more than 30 years

\footnotetext{
*Corresponding author: ildarmsu@gmail.com
} 
make it possible to form satellite observation time series, as well as to organize online access to permanently updated catalogs of satellite data and calculated products.

\section{Materials and methods}

\subsection{Data processing}

A specialized tool for remote monitoring objects has been introduced into the water resources analysis system, which implements the technology of "virtual gauging stations". The virtual gauging station is a polygon of any shape, which is saved to the database by user in an interactive mode (Fig. 1). At the same time, it is possible not only to select the period for calculating the parameter of the virtual gauging station based on the satellite images from the long-term archive, but also to analyse these images in automatic mode as the satellite data appears.

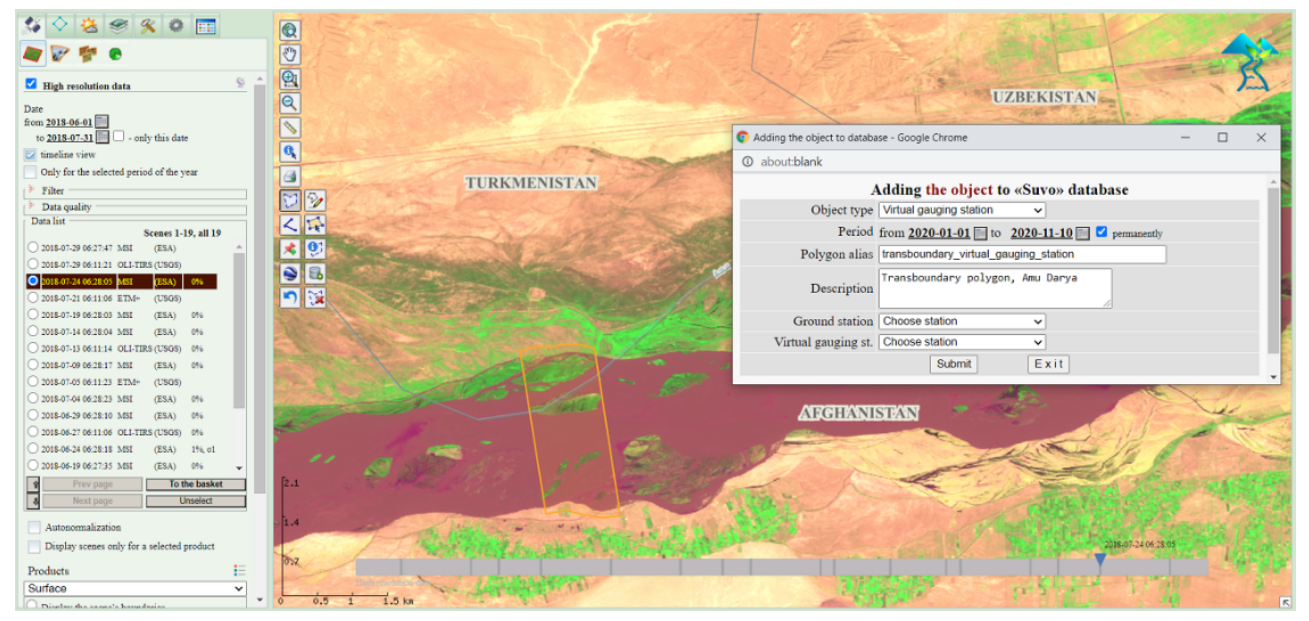

Fig. 1. Creating a virtual gauging station in EcoSatMS

Statistics collection for the space gauging station in automatic mode takes several minutes. The goal of observations calculation is the area of the water surface, computed by the modified difference water index, or MNDWI (modified normalized water index) [4]. The satellite optical images of systems OLI, TIRS (Landsat-8), MSI (Sentinel-2A, -2B), TM (Landsat $-4,-5$ ) and ETM + (Landsat-7) are used. Pixels with MNDWI value greater than 0 are taken as the water surface. The obvious advantages of this approach when assessing the state of water bodies are low resource consumption, independence from geographic location, efficiency and scalability. Observation time series obtained over a certain period are further processed using the collaborative time series analysis tool.

\subsection{The application of the virtual gauging stations technique}

The process of ground measuring stations settlement for assessing the river features often causes a number of difficulties due to the location complex terrain morphology or the features of political boundaries. Unlike an expensive physical object, setting up a polygon in an online service does not require material costs and is reduced to the work of an operator. One of the key figures in assessing the hydrological situation on the river is daily runoff. To use the data of the virtual gauging station to estimate the water discharge per 
day, it is necessary to identify the relationship between the ground figure and the calculated water surface area. Within the framework of the current research, a number of experiments were carried out, which made it possible to find a linear relationship of the area of water surface area on daily runoff at the Kerki gauging station in Turkmenistan. The results of data analysis at Kerki for 2018 and at the virtual gauging station $1 \mathrm{~km}$ away from the station are established in Fig. 2. Performed calculations were carried out using the online tool for time series analysis in EcoSatMS. At this step, the features below were also calculated:

$$
\begin{aligned}
& R=0.957-\text { Pearson coefficient of correlation } \\
& R^{2}=0.916-\text { determination coefficient } \\
& M S E=0.006-\text { mean squared error value }
\end{aligned}
$$

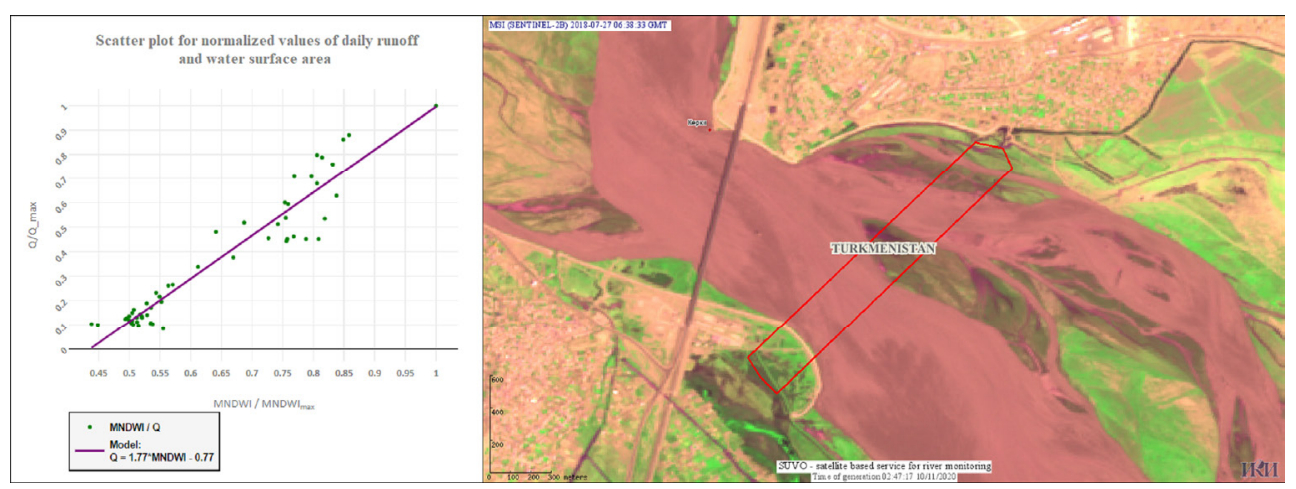

Fig. 2. Scatter plot of the daily runoff and water surface area at the virtual gauging station near Kerki and the location of the polygon

Time series of daily runoff normalized to a maximum runoff in 2018 and the figures of the water surface area normalized to a maximum of area in 2018 were used as a dataset.

After the linear relationship was found at the virtual gauging station closest to Kerki, the question of how random such a relationship can be from the point of view of the polygon positioning was investigated. In addition, it is necessary to establish whether it is possible by sequential linking of virtual gauging stations with each other and using a linear relationship to preserve the correlation, moving away from the ground station. For this, when a new polygon is created, EcoSatMS provides a feature to link the current virtual gauging station either with another one or with the ground station. This sequence of related polygons is called "virtual gauging stations net". As there is a correlation between the daily runoff and the water surface area figures, a linear model was used to calibrate the virtual gauging stations.

\subsection{Virtual gauging stations net calibration}

Let $\mathrm{Q}$ denote the daily runoff and $\mathrm{S}$ denotes water surface area figures. To produce a net according to the following technique it is necessary to save at each iteration the coefficients $a$ and $b$ of the linear equation:

$$
Q=a * S+b
$$

Calibration of the virtual gauging station means preserving the linear model coefficients and the id of the previous polygon for further daily runoff time series restoring.

The following steps are performed for each object:

$1^{\text {st }}$ iteration. The closest polygon to Kerki is linked to to ground station:

$$
Q_{0} \sim Q_{1}=a_{1} * S_{1}+b_{1}
$$


$\mathrm{n}+1^{\text {st }}$ iteration. A link between the current polygon and the previous one is created. The following calculations are performed:

1. $S_{n}=a_{n+1} * S_{n+1}+b_{n+1}$

2. $Q_{n}=a_{n} * S_{n}+b_{n} * Q_{n} \sim Q_{n+1}=\left(a_{n} * a_{n+1}\right) * S_{n+1}+a_{n} * b_{n+1}+b_{n}$

3. Daily runoff figures restoring using linear regression:

$$
Q_{n+1} \sim c_{n+1} * Q_{0}+d_{n+1}
$$

At each step of a virtual gauging stations network construction the next figures are calculated and analyzed:

- $\mathrm{S}$, ha - polygon area;

- $R\left(Q_{\text {true }}, Q_{\text {restored }}\right)$ - correlation coefficient of the series of true and restored daily runoff values;

- $R\left(Q_{\text {true }}, S_{M N D W I}\right)$ - correlation coefficient of the series of the water surface area with true daily runoffs figures (criterion to select the best polygon at the $1^{\text {st }}$ iteration);

- $F\left(Q_{\text {true }}, Q_{\text {restored }}\right)$ - ratio of variances of true and restored daily runoff series (Fisher's test). F-value is considered as a key value to find appropriate polygon at $n+1^{\text {st }}$ iteration $(n>$ $1)$;

- $M S E\left(Q_{t r u e}, S_{M N D W I}\right)$ - mean squared error for normalized daily runoff and normlized water surface area figures at the current virtual gauging station;

At each iteration, the diagram shown in Fig. 3, where the polygon set $6 \mathrm{~km}$ from the ground station and calibrated by the nearest to Kerki polygon are considered.

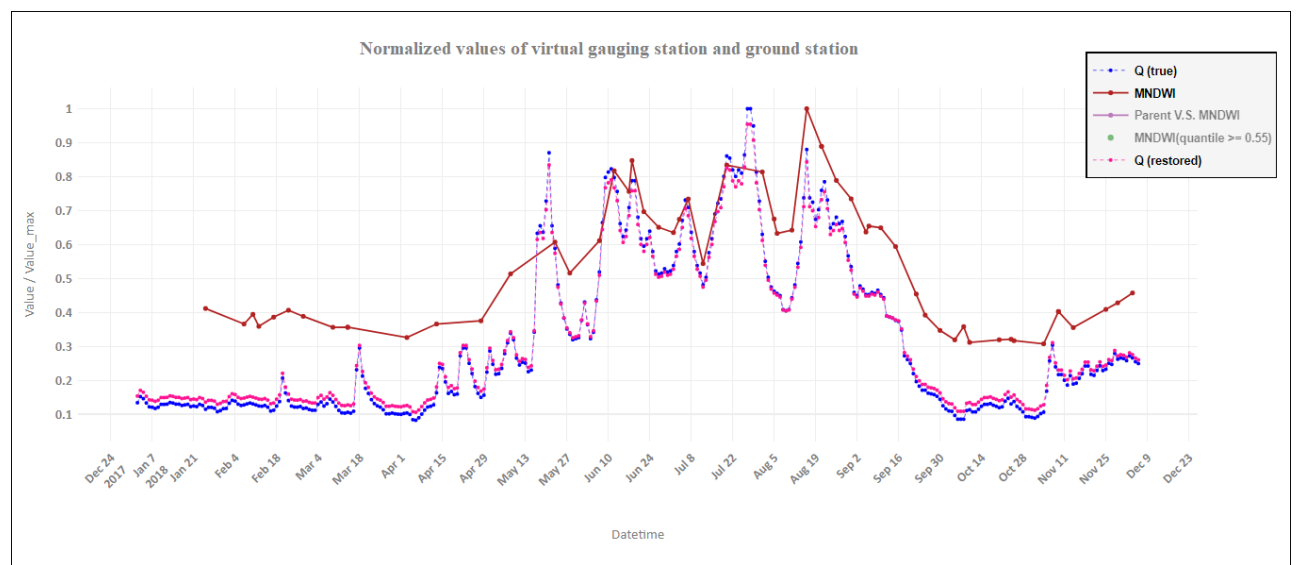

Fig. 3. The chart of restored and true daily runoff values at the virtual gauging station $6 \mathrm{~km}$ from Kerki (the $2^{\text {nd }}$ iteration of the network construction: Kerki $\rightarrow 1 \mathrm{~km} \rightarrow 6 \mathrm{~km}$ )

\section{Results}

\subsection{Polygons settlement rules}

A detailed analysis of shape effect, area, orientation of polygons and terrain morphology allowed to construct a quality network of 12 virtual gauging stations stations, which allows to save the correlation of the true measurements with the restored ones above 0.85 at a distance of over $25 \mathrm{~km}$ from the ground station. In addition, it was also found that the maximum distance at which the calibration proposed in the paper can preserve the correlation between the restored and true of daily runoff values depends on the variability of the river course structure and irrigation system throughout the entire river section. In this case, at a distance of $22 \mathrm{~km}$ upstream from Kerki a channel way takes its origins from Amu 
Darya to north. As a result, the daily runoff values will differ quantitatively from those measured at the ground station.

As a result of analyzing the shape and calculating statistics for more than 60 polygons, the following rules were formed to select the virtual gauging stations to combine them further into a network:

1. It is necessary to avoid getting into the polygon zones formed by long-term shore erosion between river streams during the low-water period;

2. The polygon should not be exposed to flooded fields at the boundary area;

3. Areas with stable snow cover should be excluded from the polygon (snow and river ice are recognized as water surface when calculating the water surface area by MNDWI) as they falsely increase the area;

4. Pittings in river bed or river terrace containing standing water make noise when calculating the water surface area;

5. The direction of the secant vector for a part of the polygon should be perpendicular to the vectors of partial flows of the river section [5].

\subsection{Test results for 2014 and 2016}

Time series of daily runoff for 2014 and 2016 were selected to check the quality of the virtual gauging stations network constructed using data of 2018. Fig. 4 performs a chart of the Fisher's test result for virtual gauging stations at different distances from Kerki. Empirically found $F=2.5$ was taken as a threshold.

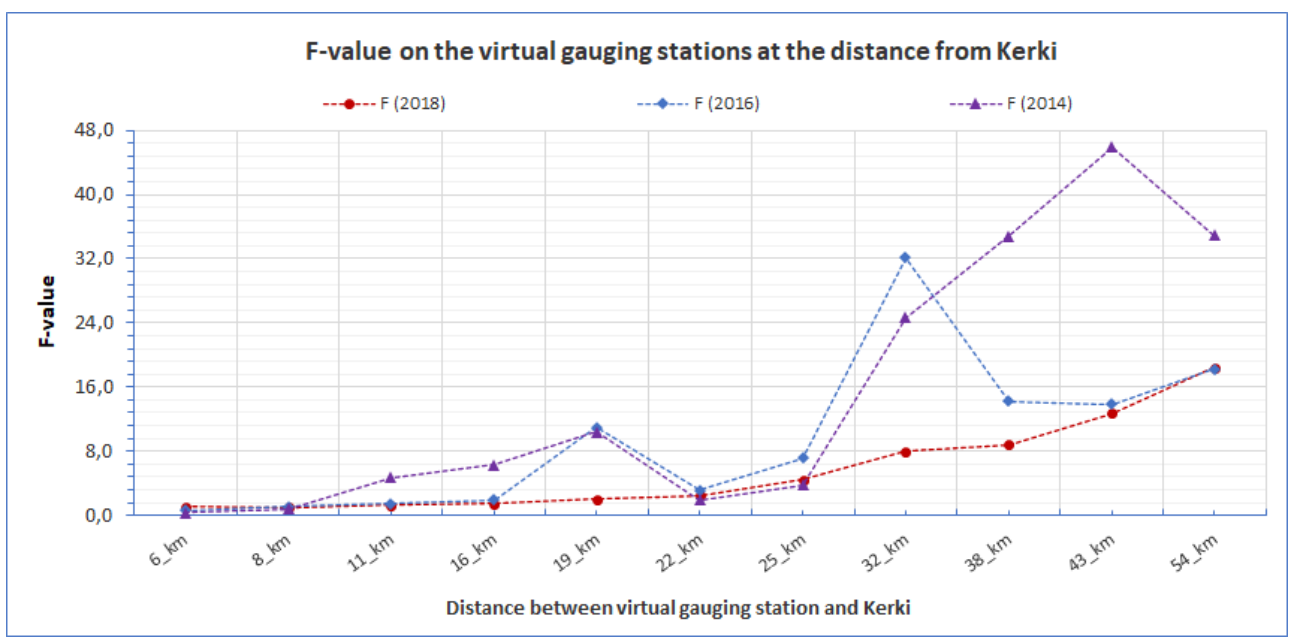

Fig. 4. F-value chart for virtual gauging stations at different distances from Kerki

The chart shows that the result model cannot be used in 2016 at a distance greater than 16 $\mathrm{km}$, and in 2014 further than $8 \mathrm{~km}$. Such indicators may perform the difference in the water regime and water amount in different years. It means that the model should be more stable in the interannual aspect and take into account more factors.

\section{Conclusion}

The described technique at the current stage helps to form a virtual gauging stations net and restore daily runoff time series at different points of the Amu Darya. Expanding the package of test data and data network calibration will help improve the accuracy of finding 
linear regression coefficients, which can make the current model more stable. To improve the accuracy and stability of the method in the interannual aspect, it is necessary to test more complex nonlinear models, as well as to include more features to model. The results obtained are the basis for implementing virtual gauging stations nets as an entity in EcoSatMS and automating the process of such networks construction.

The research was carried out using the capabilities of the «IKI-Monitoring» center for collective use [1] with the support of the project No. 19-37-90114 of the Russian Foundation for Basic Research.

\section{References}

1. Loupian E.A., Proshin A.A., Bourtsev M.A., Kashnitskiy A.V., Balashov I.V., Bartalev S.A., Konstantinova A.M., Kobets D.A., Mazurov A.A., Marchenkov V.V., Matveev A.M., Radchenko M.V., Sychugov I.G., Tolpin V.A., Uvarov I.A. Experience of development and operation of the IKI-Monitoring center for collective use of systems for archiving, processing and analyzing satellite data // Sovremennye problemy distantsionnogo zondirovaniya Zemli iz kosmosa. Vol. 16. No. 3. P. 151-170. (2019) DOI: 10.21046/2070-7401-2019-16-3-151-170.

2. Mukhamedjanov I.D., Konstantinova A.M., Uvarov I.A. Capabilities of the "IKIMonitoring" Center for collective use in organizing the satellite monitoring of the Central Asian Region // Proceedings of the International conference InterCarto/InterGIS, GI support of sustainable development of territories. Vol. 26. No. 2. P. 376-383. (2020). DOI: 10.35595/2414-9179-2020-2-26-376-383

3. Mukhamedjanov I.D., Konstantinova A.M., Loupian E.A., Gafurov A.A. Approaches to the construction of the satellite service system for Amu Darya river and its tributaries // Proceedings of the XVII All-Russian Open Conference «Actual Problems of Remote Sensing of the Earth from Space». P. 111. (2019). 11-15 November 2019, Moscow, Russia. DOI: 10.21046/17DZZconf-2019a

4. Pogorelov A.V., Lipilin D.A., Kurnosova A.S. Satellite monitoring of the Krasnodar reservoir // Geographical bulletin. No. 1(40). P. 130-137. (2017). DOI: 10.17072/2079- 7877-2017-1-130-137

5. Bykov V.D., Vasilyev A.V. Hydrometry. Leningrad, Gidrometeoizdat. (1977). 448 P. 